Article

\title{
Aerobic Treatment of Waste Process Solutions from the Semiconductor Industry: From Lab to Pilot Scale
}

\author{
Francesco Ferella *, Valentina Innocenzi, Svetlana Zueva, Valentina Corradini, Nicolò M. Ippolito, \\ Ionela P. Birloaga, Ida De Michelis, Marina Prisciandaro and Francesco Vegliò \\ Department of Industrial and Information Engineering and Economics, University of L'Aquila, \\ 67100 L'Aquila, Italy \\ * Correspondence: francesco.ferella@univaq.it; Tel.: +39-0862-434238
}

Received: 27 June 2019; Accepted: 16 July 2019; Published: 18 July 2019

\begin{abstract}
Tetramethylammonium hydroxide (TMAH) is widely used as a solvent in the semiconductor industry. After the photo-impression process, it is necessary to remove the photoresist (PR) layer from the surface of the circuits; for this purpose, a TMAH solution is usually used. This chemical compound is highly toxic and corrosive and cannot be discharged into the environment. This study was carried out in collaboration with LFoundry (SMIC group), in order to prove the feasibility of biodegradation under aerobic conditions, using microorganisms coming from the LFoundry's wastewater treatment plant (WWTP) at different operating conditions. The feed composition was modified in order to add a small but increasing amount of TMAH and PR. The aim was to verify if the increase of TMAH concentration was harmful to bacteria. The feed stream, containing TMAH and $\mathrm{PR}$, was the only carbon source for the metabolism of the aerobic microorganisms. The results of this study demonstrated an effective biological degradation of TMAH and showed a total removal efficiency of more than $99.3 \%$, with a final concentration of $7 \mathrm{mg} / \mathrm{L}$. Moreover, the kinetic parameters of the Monod model were also calculated. The results obtained from the experimental campaign were used to design a pilot plant that will treat around $25 \mathrm{~L} / \mathrm{h}$ of waste $T M A H / \mathrm{PR}$ solution.
\end{abstract}

Keywords: tetramethylammonium hydroxide; TMAH; anaerobic digestion; photoresist; wastewater

\section{Introduction}

In several production processes, special chemical compounds are often used; such chemicals cannot be easily replaced with other ones, as no substances with similar physicochemical properties are available so far. This is the case of $T M A H$, which is a quaternary ammonium salt extensively used in the semiconductor industry.

The problem lies in the high toxicity for the biota, as demonstrated by various studies [1,2]. The exposure to TMAH causes harmful effects on human health, whether ingested or inhaled: being very corrosive is harmful to both the mucous membranes and the skin in general. If TMAH is ingested, it causes burns and ulcers [3]. The acute Daphnia similis toxicity test demonstrated that the 48-h lethal

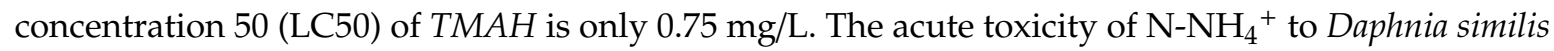
varied with the $\mathrm{pH}$ of the collected wastewater: the $48 \mathrm{~h} \mathrm{LC} 50$ values were found to vary in the range of $18.5-155 \mathrm{mg} / \mathrm{L}$ from $\mathrm{pH} 7.0$ to $\mathrm{pH} 6.5$ [2].

Mori et al. [4] also studied the TMAH effects on the aquatic environmental: the tests were carried out on seaweed and freshwater fish, in particular, the microalga Pseudokirchneriella subcapitata, the bacterium Vibrio fischeri, the fresh fish Oryziaslatipes (or rice fish) and the microcrustacean Daphnia magna. The results highlighted a strong impact on the development of these organisms because of TMAH in high concentration. The damage varies depending on the exposure level and can also lead to the death of the organisms; for this reason, it is necessary to treat it before discharging. 
Adsorption is an effective technique that can be used to remove the TMAH molecule. In particular, graphene oxide (GO) was tested in the adsorption of TMAH in different operating conditions; it was demonstrated that the adsorption capacity is around double to that of granular (GAC) and powdered (PAC) activated carbon [5] as well as zeolite Na-Y [6].

The adsorption of TMAH was also tested with ion-exchange resins like Amberlite IR-120 and Dowex HCR-W2 [7]. The adsorption with different kinds of activated carbon was also studied by Prahas et al. [8]; other studies were performed to evaluate mesoporous silicate materials or strongly and weakly acidic cation exchange resins, as well as electrodialysis in the removal of such a molecule [9-11].

Catalytic oxidation is another interesting technique investigated in the past for the removal of TMAH. Suitable catalysts, usually based on active metals like $\mathrm{Pd}-\mathrm{V}_{2} \mathrm{O}_{5}-\mathrm{WO}_{3}$ or $\mathrm{Pt}$ supported on titania-silica or alumina, were used [12]. Catalytic oxidation involves the catalyzed reaction of TMAH to $\mathrm{TMA}^{+}$and the further decomposition of $\mathrm{TMA}^{+}$to nitrogen, water, and carbon dioxide [13].

Membrane distillation is another effective treatment for the removal of TMAH and the recovery of process water in the nano-electronics industry [14].

Different authors have studied the biological degradation of TMAH, both in anaerobic and aerobic conditions, but the biological treatment of such waste solutions is still difficult in standard activated sludge plant [15].

Few studies investigated the treatment of waste solutions containing TMAH by biological processes in up-flow anaerobic sludge blanket (UASB) reactors with Methanosarcina and Methanomethylovorans bacteria: removal yields of around $90 \%$ were achieved, together with $90 \%$ of methane production $[15,16]$. Lei et al. [15] showed that effective removal is carried out under aerobic conditions in sequencing batch reactors (SBR). Hence, the anaerobic methanogenic degradation of TMAH was fully demonstrated in a batch operating mode with a $1000 \mathrm{mg} / \mathrm{L}$ synthetic solution, where the appropriate substrate composition was added. The specific TMAH degradation rate and the half-saturation constant of the enriched methanogens were $39.5 \mathrm{mg}$ TMAH/gVSS $\mathrm{h}$ and $820 \mathrm{mg} / \mathrm{L}$, according to the Monod kinetics for $T M A H$ degradation. The concentration of sulphides higher than $20 \mathrm{mg} / \mathrm{L}$ showed a heavy inhibition and slowed down the specific TMAH degradation rate of Methanomethylovorans and Methanosarcina [17].

An interesting study was carried out by means of real wastewater from a full-scale methanogenic UASB reactor that treats the sewage from the manufacturing of thin-film transistor liquid crystal displays (TFT-LCD). The batch trials demonstrated that Methanomethylovorans hollandica and Methanosarcina mazei are the dominant methanogens in the UASB responsible for TMAH degradation. In anaerobic conditions, the UASB sludge achieved a specific degradation rate of $9.5 \mathrm{mg} T M A H / \mathrm{gVSS} \cdot \mathrm{h}$, even when the original concentration of TMAH was $1500 \mathrm{mg} / \mathrm{L}$ [18]. Aerobic batch trials were also investigated, and the results showed a maximum specific degradation of $8.8 \mathrm{mg} T M A H / \mathrm{gVSS} \cdot \mathrm{h}$ with an initial TMAH of $145 \mathrm{mg} / \mathrm{L}$, but inhibition occurred when the TMAH concentrations reached $150 \mathrm{mg} / \mathrm{L}$ [18].

Anaerobic conditions were also tested by Liu et al. [19]. The anaerobic treatment of waste solution containing $340 \mathrm{mg} / \mathrm{L}$ of TMAH at room temperature was conducted in lab-scale experiments, where the methane conversion yield of TMAH reached nearly $90 \%$.

Autotrophic nitrogen removal over nitrite in a continuous anoxic up-flow bioreactor was investigated by $\mathrm{Chen}$ et al. [20]. Such a process was used to treat synthetic wastewater containing TMAH in a concentration range of $200-1000 \mathrm{mg} / \mathrm{L}$. The nitrogen average removal yield was always greater than $90 \%$ in all the trials, with a peak of $98 \%$ after a retention time of around 4.3 days. Trimethylamine and methylamine were the main biodegradation intermediates detected in the solution.

Great attention is paid to waste solutions from the semiconductor industry in those countries where many factories are located, in particular, China, Taiwan, South Korea, and Japan. This is demonstrated by the high percentage of scientific papers dealing with such a topic that comes from the aforementioned countries. Instead, Europe and the USA seem not to be aware of this problem, and this has resulted in a lack of research. The present study assesses the biological treatment in a laboratory-scale aerobic reactor of a liquid waste stream containing tetramethylammonium hydroxide $(T M A H) /$ photoresist blend. The results were then used to design a pilot-scale plant with a capacity 
of $25 \mathrm{~L} / \mathrm{h}$ in continuous operation mode. The goal of the paper was to minimize the concentration of $T M A H$ in the treated sewage released into the environment, considering the toxicological aspects and looking for the best biological technique; in particular, the objective was focused on the efficiency of the aerobic degradation as a function of the feed composition, optimized for such purpose. The novelty of the present research lies in the aerobic degradation of TMAH in high concentration (around $1800 \mathrm{mg} / \mathrm{L}$ ) with specialized microorganism strains, using a second waste stream as a carbon source.

\section{Materials and Methods}

\subsection{Feed Composition}

The wastewater (R1), provided by the company that manufactures semiconductors (LFoundry, Avezzano, Italy), contains $1600-2000 \mathrm{mg} / \mathrm{L}$ of $T M A H$, and the relevant $\mathrm{pH}$ is usually in the range of 12-13. The European Waste Code (EWC) of such a solution is 1101 12. The TMAH solution was neutralized by $5 \mathrm{~mol} / \mathrm{L} \mathrm{H}_{2} \mathrm{SO}_{4}$ solution to $\mathrm{pH} 7$, that is a value suitable for the microbial growth.

For a correct and optimal bacterial growth, the following two streams were added to the TMAH waste solution:

- a photoresist solution (R2), EWC 1406 03. This solution is an additional waste stream produced by the manufacturing processes of LFoundry: it is a mixture of organic substances, mainly 1-methoxy-2-propanol, with a total organic carbon (TOC) concentration of around $615 \mathrm{~g} / \mathrm{L}$. It was added as a source of carbon, in order to supply the optimal $\mathrm{C} / \mathrm{N}$ ratio for the bacterial metabolism, that should be 20 by weight [21]. Such a ratio is indeed too low, around 3.5 in the TMAH molecule, thus the second waste stream R2 was added to the previously mentioned stream R1;

- $\quad$ a growth medium, whose composition is shown in Table 1.

Table 1. Composition of the growth medium.

\begin{tabular}{cc}
\hline Compound & Concentration (mg/L) \\
\hline $\mathrm{CuCl}_{2}$ & 140 \\
$\mathrm{Na}_{2} \mathrm{MoO}_{4}$ & 250 \\
$\mathrm{NaHCO}_{3}$ & 820 \\
$\mathrm{~K}_{2} \mathrm{HPO}_{4}$ & 210 \\
$\mathrm{MgSO}_{4}$ & 510 \\
$\mathrm{FeCl}_{3}$ & 110 \\
Yeast Extract & 12 \\
\hline
\end{tabular}

The amount of the mixture of TMAH and PR effluents was calculated by solving the following mass balance given by the equation system:

$$
\begin{gathered}
V_{1}+V_{2}=V_{\text {TOT }} \\
\frac{C_{1} \times V_{1}+C_{2} \times V_{2}}{C_{N-T M A H} \times V_{1}}=\frac{20}{1}
\end{gathered}
$$

where $C_{1}$ is the carbon mass concentration in $T M A H$ solution, $1.1 \mathrm{~g} / \mathrm{L} ; C_{2}$ is the carbon mass concentration in the photoresist solution, $615 \mathrm{~g} / \mathrm{L} ; C_{N-T M A H}$ is the nitrogen mass concentration in the TMAH molecule, $0.31 \mathrm{~g} / \mathrm{L} ; V_{1}$ is the volume of the TMAH solution R1; $V_{2}$ is the volume of the photoresist solution R2; and $V_{T O T}$ is the total volume of the wastewater treated in the reactor. The total volume of the wastewater blend solution treated in the lab-scale bioreactor was set to $3 \mathrm{~L}$.

\subsection{Biological Tests}

The seeding activated sludge was taken from the wastewater treatment plant located in the LFoundry's site, that usually treats all the sewage coming from toilets, cleaning of some process 
equipment from the process and the canteen. The activated sludge, containing neither TMAH nor photoresist, was stored in wide neck plastic bottles. They were kept under a fume hood and left open-in contact with atmospheric air-for 14 days, to allow the complete oxidation of residual organic matter. Thus, the substrate, whose composition is listed in Table 1, was added. The feeding for the reactor was obtained by mixing $1.93 \mathrm{~L}$ of TMAH residue, $20 \mathrm{~mL}$ of photoresist, and $50 \mathrm{~mL}$ of culture mineral medium. The experimental reactor was kept at room temperature $\left(20 \pm 2{ }^{\circ} \mathrm{C}\right)$, stirred at $70 \mathrm{rpm}$ with air-oxygen saturation. Colony counts, Lowry's protein assay, and the biodiversity indexes were calculated according to the methods detailed in Moretti et al. [22]. Colony count was performed on Luria-Bertani enriched medium and AGAR-TMAH selective medium. Lowry's protein assay was carried out on lysate cells to assess the biomass production, hence the bacterial DNA was extracted from the samples. The biodiversity indexes, in particular, the range-weighted richness, functional organization, Simpson diversity index, and Simpson evenness index, were evaluated. Main genus representation in sequence reads were Comamonas $(18.3 \pm 5.7 \%)$, Pseudomonas $(18.1 \pm 5.3 \%)$, Stenotrophomonas $(12.3 \pm 3.1 \%)$, and Brevundimonas $(11.4 \pm 3.8 \%)$, while others sequence reads were spread in various groups belonging to families Sphingomonadaceae $(8.1 \pm 1.0 \%)$, Sphingobacteriaceae $(4.05 \pm 2.2 \%)$, Methylophilaceae $(4.05 \pm 3.18 \%)$, Xanthobacteraceae $(3.30 \pm 0.14 \%)$, Xanthobacter $(2.55 \pm 0.07)$, and Rhodococcus $(1.90 \pm 0.57 \%)$. The microorganism community was inoculated and adapted quickly to the change of nutrients, and stabilized over a new equilibrium state within a week when in the constant presence of TMAH and any further perturbation did not change the community structure. The biomass enrichment was obtained by means of some sequential batches, according to the sequence: (1) Batch T, from day 1 to day 6 (2 L of inoculum and $2 \mathrm{~L}$ of feeding solution); (2) Batch R, from day 7 to day 12, Batch A from day 13 to day 18, and Batch M from day 19 to day 24: at the beginning of each batch from the 7-24th day, $1 \mathrm{~L}$ of activated sludge coming from the previous batch was left in the reactor and fed with $2 \mathrm{~L}$ of feeding solution; (3) Batch $\mathrm{M}$, from day 25 to day 30, where $1 \mathrm{~L}$ of activated sludge resulting from Batch $\mathrm{M}$ was added to $2 \mathrm{~L}$ of distilled water and $50 \mathrm{~mL}$ of mineral culture medium [22].

The biological results showed an organized and stable community over time, even in the long run, composed of specialized species that were also the best selected for the desired function. After that, the biomass was concentrated by gravity and stored at $4{ }^{\circ} \mathrm{C}$ in order to be used as inoculum for the two batch cycles.

The biological tests were carried out in a bioreactor BIOSTAT ${ }^{\circledR}$ B (Sartorius, Goettingen, Germany) (Figure 1) in batch operating mode. The process conditions for the tests were: temperature $25^{\circ} \mathrm{C}, \mathrm{pH} 7$, stirring speed $70 \mathrm{rpm}$, oxygen flow-rate of $2.0 \mathrm{~L} / \mathrm{min}$, controlled and regulated by the control unit of the bioreactor, whose nominal capacity was $3.5 \mathrm{~L}$.

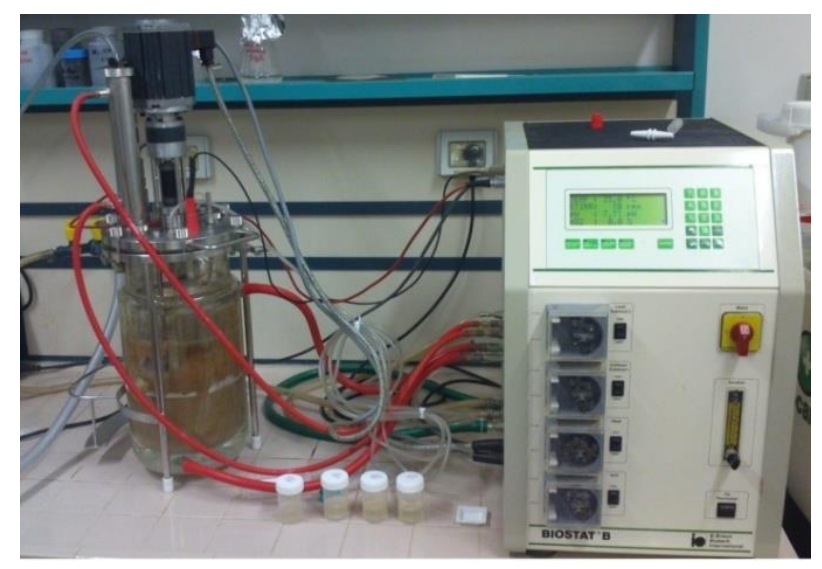

Figure 1. BIOSTAT ${ }^{\circledR} \mathrm{B}$ and its control unit.

Two sequential batch cycles were carried out; such cycles were consecutive in order to confirm the results with different waste solution samples. At the end of the first cycle, mixing and aeration 
were switched off, so that the biomass could settle; thus, the supernatant was removed by a peristaltic pump and disposed of, whereas the settled biomass was centrifuged in order to remove the remaining solution. Afterward, the fresh mixture $(2678 \mathrm{~mL}$ of $T M A H+22 \mathrm{~mL}$ of PR solutions) was added together with $300 \mathrm{~mL}$ of growth medium and the recycled biomass. At the end of each cycle, the total volume of the TMAH/PR wastewater mixture and growth medium was removed and disposed of. The concentration of $T M A H$, after dilution with the photoresist and sludge, was $1780 \mathrm{mg} / \mathrm{L}$ and $1625 \mathrm{mg} / \mathrm{L}$ for batch cycle 1 and 2, respectively. The batch time for each cycle was 21days, whereas the solid retention time (SRT) was 42 days. The composition of the two solutions, after blending, is listed in Table 2.

Table 2. Composition of the solutions for the two batch tests.

\begin{tabular}{ccc}
\hline Parameter & Batch $\mathbf{1}(\mathbf{m g} / \mathrm{L})$ & Batch $\mathbf{2}(\mathbf{m g} / \mathbf{L})$ \\
\hline $\mathrm{pH}$ & 7.20 & 6.95 \\
$\mathrm{COD}$ & 5085 & 4863 \\
$\mathrm{TMAH}$ & 1780 & 1625 \\
$\mathrm{NH}_{4}^{+}$ & 75 & 62 \\
$\mathrm{~F}^{-}$ & 0.04 & 0.02 \\
$\mathrm{NO}_{3}^{-}$ & $<0.01$ & $<0.01$ \\
$\mathrm{Cl}^{-}$ & 0.09 & 0.06 \\
$\mathrm{Sb}, \mathrm{As}, \mathrm{Cd}, \mathrm{Cr}, \mathrm{Hg}, \mathrm{Ni}, \mathrm{Pb}, \mathrm{K}, \mathrm{Se}, \mathrm{Cu}$ & $<0.01$ & $<0.01$ \\
$\mathrm{Na}$ & 0.55 & 0.71 \\
\hline
\end{tabular}

The mixture's $\mathrm{pH}$ was adjusted to the optimal value (i.e., 7) by the addition of $\mathrm{H}_{2} \mathrm{SO}_{4}(96 \% \mathrm{wt})$ or $\mathrm{NaOH}(35 \% \mathrm{wt})$ from the initial value of 12.4 .

Every day, one sample of $100 \mathrm{~mL}$ was collected and centrifuged at $5000 \mathrm{rpm}$. The supernatant was used to determine the $\mathrm{pH}$ (Seven Compact $\mathrm{pH}$-meter, Mettler Toledo), TMAH (Ion Chromatograph Dionex DX5000), and ammonium ion (Nessler's reagent method) concentrations, whereas the total suspended solids (TSS) were determined after drying of the settled material at $105^{\circ} \mathrm{C}$ for $24 \mathrm{~h}$.

The sample's volume was refilled by the addition of the growth medium. The kinetic parameters of the Monod model were also calculated for the design of the pilot bioreactor [21].

\section{Results and Discussion}

\subsection{Kinetic Model}

It was assumed that the kinetics of the microorganism population could be represented by the Monod model (Equation (3)):

$$
\mu=\frac{\mu_{\max } \times S}{K_{S}+S}
$$

where $\mu$ is the specific growth rate of the microorganisms $\left(\mathrm{h}^{-1}\right), \mu_{\max }$ is the maximum specific growth rate $\left(\mathrm{h}^{-1}\right), S$ is the concentration of the limiting substrate for growth $(\mathrm{mg} / \mathrm{L})$, and $K_{S}$ is the half-velocity constant, that is, the value of $S$ corresponding to $\mu / \mu_{\max }=0.5(\mathrm{mg} / \mathrm{L})$. The specific growth rate $(\mu)$ was calculated from an overall mass balance for the biomass at stationary conditions.

One single batch test was sufficient to derive the specific growth rate, by solving the system of linear first order differential equations:

$$
\begin{aligned}
& \frac{d X}{d t}=\mu \times X \\
& \frac{d S}{d t}=-\sigma \times X \\
& \frac{d P}{d t}=\pi \times X
\end{aligned}
$$


where $X, S$, and $P$ are the concentrations of microorganisms $(\mathrm{mg} / \mathrm{L}), T M A H(\mathrm{mg} / \mathrm{L})$, and ammonium ion (mg/L), respectively, and $\mu, \sigma$, and $\pi$ are the specific growth rate, substrate consumption rate, and product generation rate $\left(\mathrm{h}^{-1}\right)$. These three equations have to be coupled with the well-known Monod (Equation (3)), Pirt (Equation (7)), and Luedeking-Piret (Equation (8)) equations:

$$
\begin{gathered}
\sigma=\frac{1}{Y_{X / S}^{G}} \times \mu+m \\
\pi=\alpha \times \mu+\beta
\end{gathered}
$$

where the coefficients $m$ and $\beta$ are null (product associated to the growth), the biomass yield $Y^{G} \mathrm{X} / \mathrm{S}$ is $0.34 \mathrm{~g}$ of biomass per $\mathrm{g}$ of substrate, and $\alpha=0.2 \mathrm{~g}$ of ammonium per $\mathrm{g}$ of biomass (experimental values). The detailed calculation can be found in Innocenzi et al. [21]. Such an approach allows the fitting of substrate depletion data versus time to the integrated Monod equation by using nonlinear regression, which is advantageous since $\mu_{\max }$ and $K_{S}$ may be calculated from a single progress curve [23].

From the analysis of the data collected from the tests carried out with the bench bioreactor, the following kinetic parameters were calculated:

- $\mu_{\max }=0.0425 \pm 0.0034 \mathrm{~h}^{-1}$;

- $K_{S}=800 \pm 51 \mathrm{mg} / \mathrm{L}$.

These data were used to design the optimal configuration of the biological equipment for the pilot plant.

\subsection{Biological Tests}

Figure 2 shows the $\mathrm{pH}, \mathrm{NH}_{4}{ }^{+}, \mathrm{TMAH}$ and TSS trends for each batch cycle. From Figure 2, the following conclusions can be inferred:

- the $\mathrm{pH}$ value changed during each cycle: it increased to alkaline values and then came back towards neutral values after several days. This was apparently due to a buffering effect of the growth medium;

- $\mathrm{NH}_{4}{ }^{+}$concentration increased with time: this was a clear indication of the TMAH degradation and indeed started after the adaptation period of 36-48 h;

- the TMAH concentration trend showed a rapid degradation and a further decrease toward zero, after the adaptation period. It is possible to hypothesize that, after nearly two days, the TMAH was adsorbed on the biomass and, afterward, was gradually decomposed, reaching concentrations very low if compared to the initial one. The final TMAH concentration obtained in the two batch cycles was 7 and $4 \mathrm{mg} / \mathrm{L}$;

- the biomass concentration increased up to the tenth/eleventh day, but after that, it was rather constant, at around $1300-1500 \mathrm{mg} / \mathrm{L}$.

Figure 3 shows the TMAH degradation and the resulting $\mathrm{NH}_{4}{ }^{+}$production for each cycle; the $T M A H$ removal was higher than $99 \%$, and this confirms the effectiveness of the biological process carried out in the experimental campaign. Hu et al. [18] stated that the aerobic sludge with a concentration of $2000 \mathrm{mg} / \mathrm{L}$ can gradually decompose $T M A H$, after several hours of inhibition, but the reduction in such ability usually occurs when the TMAH concentration reaches $150 \mathrm{mg} / \mathrm{L}$. Instead, Lei et al. [15] found that an acclimated aerobic sludge reduces the inhibitory effect of $T M A H$ up to $300 \mathrm{mg} / \mathrm{L}$, but the aerobic process is not recommended for wastewater containing more than $1000 \mathrm{mg} / \mathrm{L}$ of such a molecule. Nevertheless, the 14-day acclimated strains were able to degrade higher concentrations of TMAH. 


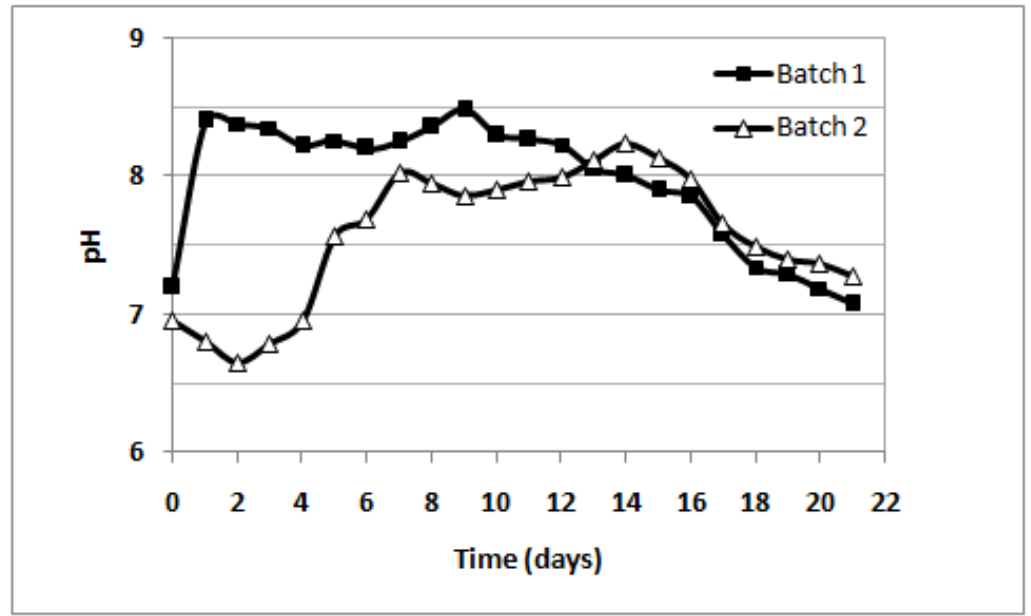

(a)

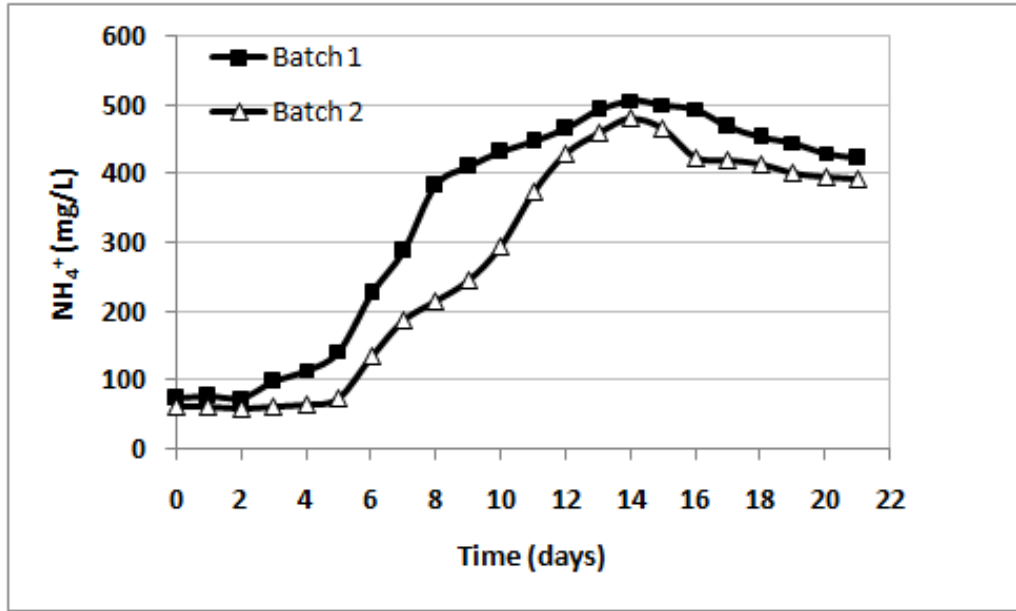

(b)

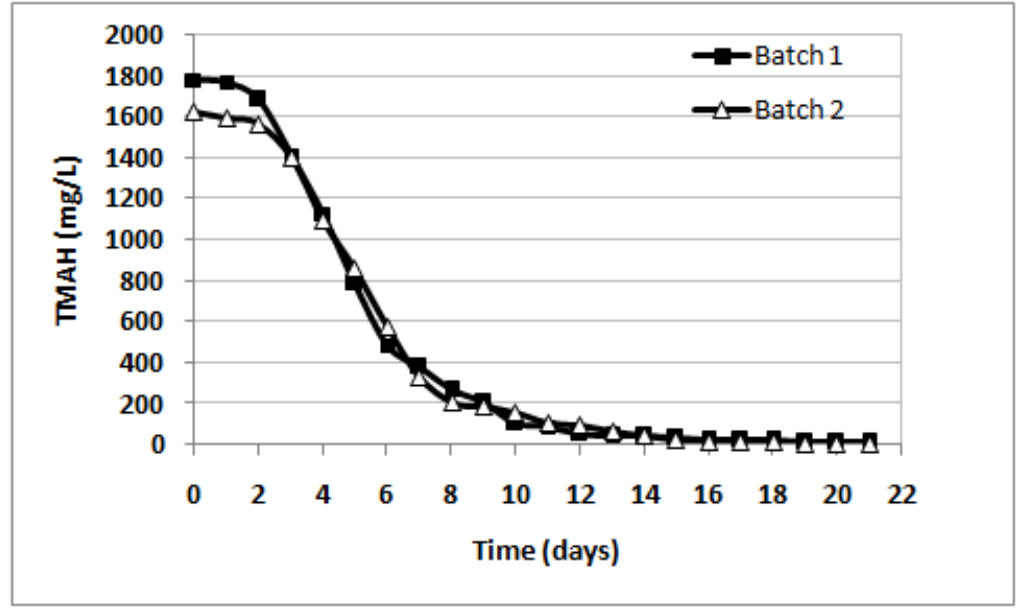

(c)

Figure 2. Cont. 


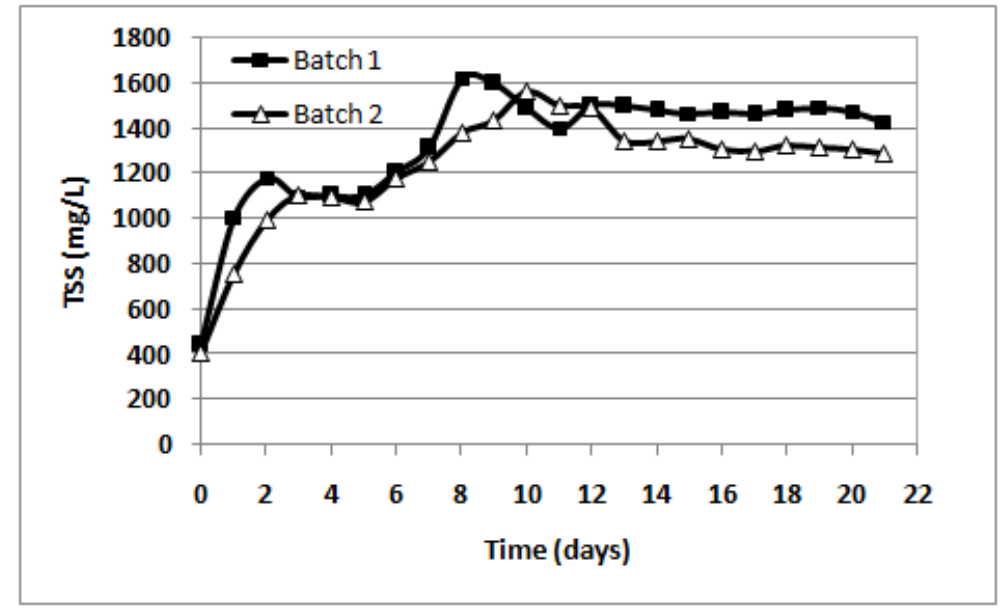

(d)

Figure 2. $\mathrm{pH}(\mathbf{a}), \mathrm{NH}_{4}{ }^{+}(\mathbf{b}), T M A H(\mathbf{c})$,and TSS (d) trends for the effluent in batches 1 and 2.

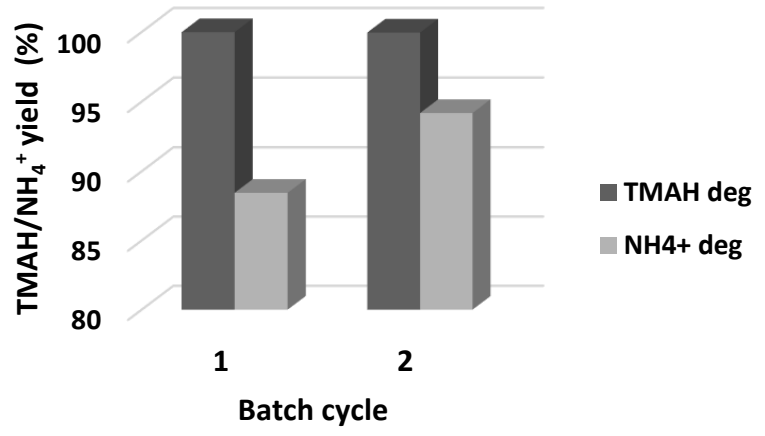

Figure 3. Degradation and $\mathrm{NH}_{4}{ }^{+}$ion production for each cycle.

Comparing these results with those obtained in other prior experiments, where the feeding conditions were different (i.e.,1.5 L of TMAH/PR mixture feed $(1.488 \mathrm{~mL}$ of TMAH mixed with $12 \mathrm{~mL}$ of PR) plus $1.5 \mathrm{~L}$ of growth medium, with a TMAH concentration of $992 \mathrm{mg} / \mathrm{L}$ ), it is possible to observe that the increase in the initial TMAH concentration from $992 \mathrm{mg} / \mathrm{L}$ to $1780 \mathrm{~g} / \mathrm{L}$ does not cause harmful effects on bacteria: as a matter of fact, the population of the microorganisms did not show any slowdown in their metabolic activity. The results of such tests are reported in Figure 4: six batch cycles were carried out with the same procedure described in Section $2.2\left(25^{\circ} \mathrm{C}\right.$, stirring at $70 \mathrm{rpm}, 2 \mathrm{~L} / \mathrm{min}$ of $\mathrm{O}_{2}$, batch time 21 days). The final TMAH concentration was in the range of $2-5 \mathrm{mg} / \mathrm{L}$.

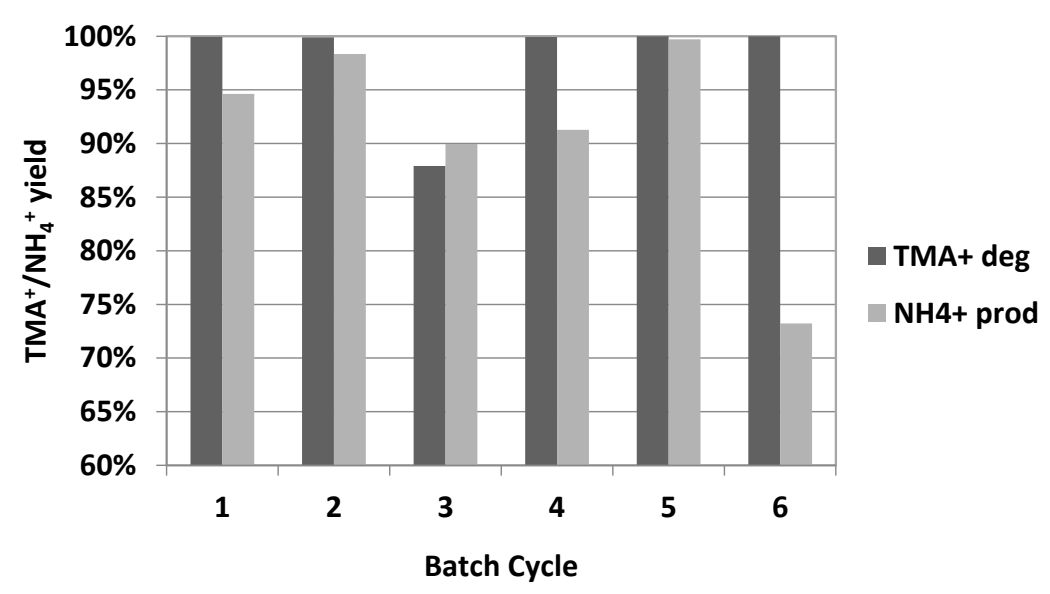

Figure 4. Degradation and $\mathrm{NH}_{4}{ }^{+}$ion formation for previous experiments with different feed condition (50\% waste solution (TMAH-PR)/50\% growth medium), $\mathrm{TMAH}_{0}=992 \mathrm{mg} / \mathrm{L}$. 


\section{Pilot Plant}

At the moment, LFoundry neutralizes the TMAH by $\mathrm{H}_{2} \mathrm{SO}_{4}$ and $\mathrm{NaOH}$, and the solution passes through an ion exchange resin filter from which the TMAH is stripped by another solution: in this manner, the TMAH can be concentrated and the resulting volume is lower. This solution is thus stored in a big tank and sent to an external plant authorized for the treatment of such waste. In addition, LFoundry also owns a conventional activated sludge system that already treats the wastewater from toilets, the canteen, the solution from which the TMAH is removed (from the ion-exchange) and other process wastewaters. Hence, the aim of LFoundry is to construct an upstream plant that can treat such particular liquid stream, instead of being disposed of externally, saving a significant amount of the annual operating costs relevant to the waste treatment.

The Monod model was used to design the pilot-scale bioreactor. The design was optimized by applying the minimization of the total volume, using three reactors in series [24].

Such a configuration, in continuous operating mode, is composed of three bioreactors in series that allow a remarkable saving in the total volume required for the treatment of the TMAH/PR solution. The volume of each bioreactor is indeed around $1.1 \mathrm{~m}^{3}$ (total volume $3.3 \mathrm{~m}^{3}$ ), whereas the volume of one single bioreactor would have been $10 \mathrm{~m}^{3}$. The pilot plant is housed in two $40 \mathrm{ft}$ standard containers and can treat three types of industrial effluents produced by LFoundry: line 1 treats the TMAH/PR mixed stream by the biological process, whereas line 2 (BOE) and line 3 (SEZ) treat other two waste streams containing high concentrations of nitrates, fluorides, and acetic acid. The first container includes one neutralization reactor, a storage tank and three biological reactors in series; the second container houses the equipment to treat the other two waste solutions by using physicochemical operations, in particular, one reactor, a plate and frame filter, and some tanks to store the effluents before and after the treatments. Some pictures of the pilot plant are shown in Figure 5.

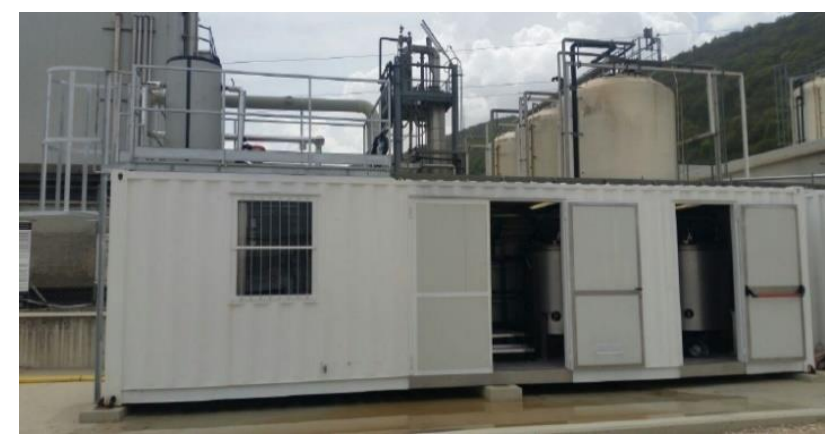

(a)

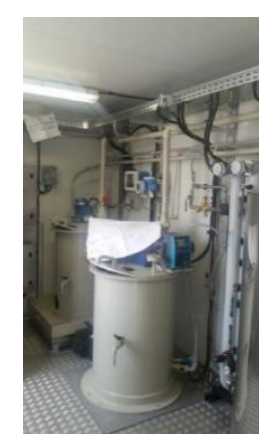

(b)

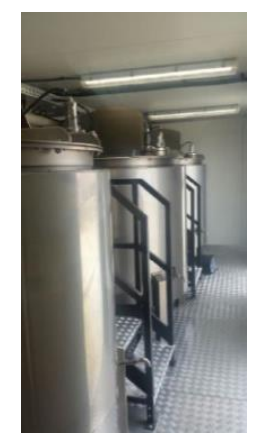

(c)

Figure 5. $40 \mathrm{ft}$ container housing the pilot plant (a), storage tank (b), and the three bioreactors (c).

The pilot-scale tests began in the winter 2018 and are currently being carried out for optimization purposes; the overall results will be published as soon as the experimental campaign ends. Nonetheless, a preliminary design of the full-scale plant was also carried out, considering that the amount of the $T M A H /$ photoresist mixture currently produced at LFoundry is $6300 \mathrm{t} /$ year. The optimized configuration with three reactors in series, $30 \mathrm{~m}^{3}$ each, with pumps, two tanks for neutralization and final storage, PLC, and control devices, electricals, and more, will require an investment of around $€ 1.64$ million. The total operating costs were estimated to be nearly $90 € / t$, lower than the current cost paid for the external disposal of such solutions, that amounts to $140 € / t$. The payback time is 4.75 years. LFoundry will evaluate the possibility of constructing the fully automated plant once a more accurate economic analysis, based on the pilot-scale data, is available.

\section{Conclusions}

The experiments carried out with TMAH/PR wastewater showed that the aerobic biological treatment is able to remove the TMAH molecule. In the present case, the mixture was composed 
of $10 \%$ of growth medium and $90 \%$ of TMAH/PR wastewater, while in other previous experiments, such a composition was $50 \%$ growth medium and $50 \% T M A H / P R$. For each cycle that lasted 21 days, the TMAH concentration was reduced to $4-7 \mathrm{mg} / \mathrm{L}$, with removal yields greater than $99.3 \%$ : this means that the microorganism populations already present in the sludge from the LFoundry's WWTP can adapt their metabolism and use the TMAH as substrate, when photoresist, another waste solution, is dosed as carbon source. Moreover, the optimal composition of the growth medium and all the process parameters like $\mathrm{pH}$, temperature, $\mathrm{O}_{2}$ flow-rate, and stirring were optimized. The kinetic parameters of the Monod model were also obtained in order to design the pilot plant, whose capacity was set at $25 \mathrm{~L} / \mathrm{h}$. The adapted microorganisms were thus used for the inoculum in the pilot plant, where three bioreactors in series were chosen in order to reduce the total volume required by the process. The volume of each reactor is around $1.1 \mathrm{~m}^{3}$. The pilot-scale experimental campaign is currently being carried out.

Author Contributions: Conceptualization, I.D.M. and M.P.; Methodology, S.Z.; Experimental Tests, V.I., N.M.I., V.C. and S.Z.; Analytical Measurements, V.I., S.Z., I.P.B. and N.M.I.; Investigation, I.P.B.; Data Curation, V.I.; Writing-Original Draft Preparation, F.F.; Writing-Review and Editing, F.F. and N.M.I.; Supervision, M.P. and F.V.; Project Administration, V.C. and I.D.M.; Funding Acquisition, F.V.

Funding: This research was funded by the EUROPEAN COMMISSION, grant number LIFE15 ENV/IT/000332, Project LIFE BITMAPS (http://www.lifebitmaps.eu/).

Acknowledgments: Authors kindly acknowledge the LFoundry's personnel for their precious help and work in the characterization of the samples and in the pilot-plant tests.

Conflicts of Interest: The authors declare no conflict of interest.

\section{References}

1. Lin, C.C.; Yang, C.C.; Ger, J.; Deng, J.F.; Hung, D.Z. TMAH poisoning. Clin. Toxicol. 2010, 48, 213-217. [CrossRef] [PubMed]

2. Lee, C.Y.; Wang, L.M.; Ngo, M.H.; Chen, T.H.; Cheng, H.H. Acute toxicity assessment of TFT-LCD wastewater using Daphnia similis and Cyprinus carpio. Process Saf. Environ. Protect. 2016, 104, 499-506. [CrossRef]

3. Lee, C.H.; Wang, C.L.; Lin, H.F.; Chai, C.Y.; Hong, M.Y.; Ho, C.K. Toxicity of tetramethylammonium hydroxide: Review of two fatal cases of dermal exposure and development of an animal model. Toxicol. Ind. Health 2011, 27, 497-503. [CrossRef] [PubMed]

4. Mori, I.C.; Arias-Barreiro, C.R.; Koutsaftis, A.; Ogo, A.; Kawano, T.; Yoshizuka, K.; Inayat-Hussain, S.H.; Aoyama, I. Toxicity of tetramethylammonium hydroxide to aquatic organisms and its synergistic action with potassium iodide. Chemosphere 2015, 120, 299-304. [CrossRef] [PubMed]

5. Chang, S.; Lin, K.Y.A.; Lu, C. Efficient adsorptive removal of tetramethylammonium hydroxide (TMAH) from water using graphene oxide. Sep. Purif. Technol. 2014, 133, 99-107. [CrossRef]

6. Chang, S.; Lu, C.; Lin, K.Y.A. Comparisons of kinetics, thermodynamics and regeneration of tetramethylammonium hydroxide adsorption in aqueous solution with graphene oxide, zeolite and activated carbon. Appl. Surf. Sci. 2015, 326, 187-194. [CrossRef]

7. Shu, H.Y.; Chang, M.C.; Liu, J.J. Cation resin fixed-bed column for the recovery of valuable TMAH reagent from the wastewater. Process Saf. Environ. Prot. 2016, 104, 571-586. [CrossRef]

8. Prahas, D.; Liu, J.C.; Ismadji, S.; Wang, M. Adsorption of tetramethylammonium hydroxide on activated carbon. J. Environ. Eng. 2012, 138, 232-238. [CrossRef]

9. Kelleher, B.P.; Doyle, A.M.; O'Dwyer, T.F.; Hodnett, B.K. Preparation and use of a mesoporous silicate material for the removal of tetramethylammonium hydroxide (TMAH) from aqueous solution. J. Chem. Technol. Biotechnol. 2001, 76, 1216-1222. [CrossRef]

10. Nishihama, S.; Takatori, K.; Yoshizuka, K. Separation and recovery of tetramethylammonium hydroxide with zeolitic adsorbents. Ion Exch. Lett. 2011, 3, 1-6.

11. Citraningrum, H.M.; Liu, J.C.; Chern, J.M. Removal of tetramethylammonium hydroxide from solution using ion exchange. IEEE Trans. Semicond. Manuf. 2013, 26, 214-220. [CrossRef]

12. Hirano, K.; Okamura, J.; Taira, T.; Sano, K.; Toyoda, A.; Ikeda, M. An efficient treatment technique for TMAH wastewater by catalytic oxidation. IEEE Trans. Semicond. Manuf. 2001, 14, 202-206. [CrossRef] 
13. Wang, C.W.; Liang, C. Oxidative degradation of TMAH solution with UV persulfate activation. Chem. Eng. J. 2014, 254, 472-478. [CrossRef]

14. Noor, I.; Coenen, J.; Martin, A.; Dahl, O.; Aslin, M. Experimental investigation and techno-economic analysis of tetramethylammonium hydroxide removal from wastewater in nanoelectronics manufacturing via membrane distillation. J. Membr. Sci. 2019, 579, 283-293. [CrossRef]

15. Lei, C.N.; Whang, L.M.; Chen, P.C. Biological treatment of thin-film transistor liquid crystal display (TFT-LCD) wastewater using aerobic and anoxic/oxic sequencing batch reactors. Chemosphere 2010, 81, 57-64. [CrossRef]

16. Chang, K.F.; Yang, S.Y.; You, H.S.; Pan, J.R. Anaerobic treatment of tetramethylammonium hydroxide (TMAH) containing wastewater. IEEE Trans. Semicond. Manuf. 2008, 21, 486-491. [CrossRef]

17. Hu, T.H.; Whang, L.M.; Huang, C.Y. Methanogenic degradation of tetramethylammonium hydroxide by Methanomethylovorans and Methanosarcina. J. Hazard. Mater. 2018, 357, 180-186. [CrossRef]

18. Hu, T.H.; Whang, L.M.; Liu, P.W.G.; Hung, Y.C.; Chen, H.W.; Lin, L.B.; Chen, C.F.; Chen, S.K.; Hsu, S.F.; Shen, W.; et al. Biological treatment of TMAH (tetra-methyl ammonium hydroxide) in a full-scale TFT-LCD wastewater treatment plant. Bioresour. Technol. 2012, 113, 303-310. [CrossRef]

19. Liu, B.; Yoshinaga, K.; Wu, J.H.; Chen, W.Y.; Terashima, M.; Goel, R.; Pangallo, D.; Yasui, H. Kinetic analysis of biological degradation for tetramethylammonium hydroxide (TMAH) in the anaerobic activated sludge system at ambient temperature. Biochem. Eng. J. 2016, 114, 42-49. [CrossRef]

20. Chen, S.Y.; Lu, L.A.; Lin, J.G. Biodegradation of tetramethylammonium hydroxide (TMAH) in completely autotrophic nitrogen removal over nitrite (CANON) process. Bioresour. Technol. 2016, 210, 88-93. [CrossRef]

21. Innocenzi, V.; Zueva, S.; Prisciandaro, M.; De Michelis, I.; Di Renzo, A.; Mazziotti Di Celso, G.; Vegliò, F. Treatment of TMAH solutions from the microelectronics industry: A combined process scheme. J. Water Process Eng. 2019, 31, 100780. [CrossRef]

22. Moretti, G.; Matteucci, F.; Saraullo, M.; Vegliò, F.; Del Gallo, M. Selection of a very active microbial community for the coupled treatment of tetramethylammonium hydroxide and photoresist in aqueous solutions. Int. J. Environ. Res. Public Health 2018, 15, 41. [CrossRef] [PubMed]

23. Robinson, J.A.; Tiedje, J.M. Nonlinear estimation of Monod growth kinetic parameters from a single substrate depletion curve. Appl. Environ. Microbiol. 1983, 45, 1453-1458. [PubMed]

24. McDuffie, N.G. Bioreactor Design Fundamentals, 1st ed.; Butterworth-Heinermann: London, UK, 1991.

(C) 2019 by the authors. Licensee MDPI, Basel, Switzerland. This article is an open access article distributed under the terms and conditions of the Creative Commons Attribution (CC BY) license (http://creativecommons.org/licenses/by/4.0/). 